\title{
Desafios contemporâneos e o campo das políticas educacionais: tensões e inflexões
}

Apresentamos aos leitores mais um número da Revista Brasileira de Políticas e Administração da Educação, a RBPAE, cuja conclusão ocorre em um momento no qual a sociedade brasileira se depara com um denso e caloroso debate acerca da intensificação de uma grave crise política e econômica. Entendemos que os interesses em disputa, nesse contexto, ameaçam a democracia e o Estado de Direito, tendo em vista a explícita judicialização do campo político, as alianças entre forças políticas e grandes empresas financiadoras de campanhas eleitorais, e um forte apelo midiático e espetaculoso que acirra e estimula a divisão do Brasil entre classes antagônicas, geográfica e socialmente distintas. Este fenômeno coloca, à direita, os defensores das políticas (neo) liberais ou o Estado Mínimo e, à esquerda, os que defendem a social democracia, ou o Estado provedor de políticas sociais. Observa-se assim, que a pretendida conciliação entre essas duas perspectivas esbarra na histórica luta de classes, ou seja, trata-se de pretensiosa utopia que a História já demonstrou ser inconciliável.

O que se assiste no Brasil, portanto, é uma clara tentativa de retomada do Estado pelas forças políticas aliadas ao grande capital internacional, adeptas dos princípios que elegem a meritocracia, o individualismo e a privatização de serviços sociais como condutores das políticas públicas, em detrimento da inclusão social, do coletivo solidário e da garantia de serviços públicos de proteção social que permitam a redução das desigualdades sociais.

Nesse cenário, a RBPAE reafirma sua posição em favor da soberania do Estado brasileiro e do respeito à democracia, da efetivação das políticas educacionais previstas na LDB e no PNE e na defesa da educação pública, gratuita, laica e de qualidade social. Dessa forma trabalhamos diuturnamente, de maneira propositiva e sistemática, para contribuir para esse debate por meio da divulgação de estudos e pesquisas acadêmicas cujo escopo é, justamente, as políticas e a gestão da educação numa perspectiva democrático-participativa.

Nesta edição, seguindo sua linha editorial, a RBPAE apresenta um conjunto de produções científicas que abordam temas diversos, dentre os quais, as políticas de avaliação e dimensões de desigualdade educacional no Brasil, políticas educacionais para a Amazônia, políticas e ações de formação e trabalho docente, expansão da educação superior e gestão da educação. 
Marilda Pasqual Schneider e Camila Regina Rostirola dedicam-se, no debate sobre Estado-Avaliador: reflexões sobre sua evolução no Brasil, a deslindar características das três fases da adoção da avaliação no campo da educação: (i) de vinculação da ideologia neoliberal às políticas de avaliação e adesão à avaliação de larga escala, (ii) pela adesão à formas de avaliação internacional e (iii) pelos processos de transnacionalização da prática avaliativa. Apontam tendências e tensões, assim como o reconhecimento de seus indícios nas políticas de avaliação educacional praticadas no Brasil a partir da apresentação do desenvolvimento do Estado-Avaliador no país. As autoras demonstram que foi possível reconhecer no Brasil a presença nítida das duas primeiras fases e que, mesmo com certa prudência, podem-se verificar no país algumas características da terceira fase.

O estudo das três dimensões da desigualdade educacional no Brasil foi o tema escolhido por Gabriela Thomazinho Clementino Sampaio e Romualdo Portela de Oliveira por meio do artigo Dimensões da desigualdade educacional no Brasil, que apresenta dados e discussões sobre a concepção de desigualdade de acesso, desigualdade de tratamento e desigualdade de conhecimento. Apontam que o estudo da desigualdade educacional é composto por múltiplas dimensões, salientam a necessidade de divulgação de alguns indicadores relevantes, de examinar mais profundamente como estas dimensões se influenciam mutuamente, e de discutir os meios de reduzir a desigualdade educacional.

Eraldo Souza Carmo e Maria Sueli Corrêa Prazeres discutem em Políticas educacionais para a Amaẑônia: teorias, práticas e contradições, as configurações das políticas educacionais às populações do campo na Amazônia, a partir da estrutura do estado capitalista, concluindo que as políticas que emergem dos órgãos centrais para realidades específicas desconsidera as heterogeneidades locais.

Abrindo a discussão sobre a formação e trabalho docente no Brasil, o artigo Produção de conhecimento sobre politicas para formação e carreira docentes no Brasil, de Isabel Melero Bello, Marieta Gouvêa de Oliveira Penna e Mirna Ribeiro Lima da Silva analisa a produção acadêmica sobre políticas para a formação e carreira docentes, no período de 2000-2010 no Brasil, por meio de resumos de teses e dissertações da área da educação. As autoras concluem que tem havido aumento progressivo de pesquisas na área e que estas se encontram pulverizadas entre diversas linhas de investigação.

André Rodrigues Guimarães e Vera Lúcia Jacob Chaves investigaram A intensificação do trabalho docente universitário: aceitações e resistências, com o objetivo de analisar como os professores universitários interagem com o processo de intensificação do trabalho. Os resultados mostram duas visões: parte dos professores não percebe criticamente o processo de intensificação do seu trabalho e parte atribui esta intensificação à mercantilização das suas funções, como 
consequência das mudanças macroestruturais que submetem a universidade aos interesses do mercado.

$\mathrm{O}$ artigo de Ezequiel Ferreira Barbosa e Maria Cândida Muler, intitulado Formação docente: saberes e práticas necessárias para a escola contemporânea, tem por objetivo "abordar questões referentes à educação contemporânea e o papel da escola como espaço social de reflexão na luta contra as desigualdades e como instrumento necessário para a construção da cidadania". Reflete, ainda, sobre a formação docente e seu papel como agente transformador na sociedade.

Fechando as discussões que envolvem o trabalho docente, a investigação A dimensão meritocrática dos testes estandardizados e a responsabilização unilateral dos docentes, de Leonice Matilde Richter, Vilma Aparecida Souza e Maria Vieira Silva, analisa, através de uma pesquisa empírica, a relação entre as políticas educacionais elaboradas pelo Estado e a intensificação do trabalho docente mediante testes estandardizados na educação brasileira, entendida como estratégia inerente à sua lógica gerencial.

Com o artigo Expansão da Educação Superior no MERCOSUL: análise do cenário brasileiro, as possibilidades trazidas pela educação a distância e a relevância de bases curriculares transnacionais, Warlley Ferreira Sahb e Fernando José de Almeida realizam uma análise da atual política de integração educacional da América do Sul a partir da conjuntura brasileira, abordando seu processo de expansão e a importância do fomento de um sistema de educação transnacional na América do Sul, apresentando dados do histórico da educação a distância, processo de integração e internacionalização da educação no MERCOSUL e a relação do uso das tecnologias com a expansão.

Elton Luiz Nardi é autor de Itinerários da participação na gestão de escolas públicas de educação básica, que recorre aos resultados de duas pesquisas realizadas no período 2010-2012 em escolas de redes municipais do estado de Santa Catarina e analisa, por meio de análise documental e de pesquisa empírica, as opções normativo institucionais relacionadas à gestão democrática do ensino público e ações delineadas por escolas de Educação Básica visando à participação da comunidade escolar.

$\mathrm{O}$ artigo Sistemas estaduais de avaliação: interfaces com qualidade e gestão da educação, de Cristiane Machado, Ocimar Munhoz Alavarse e Paulo Henrique Arcas, procura desvendar possíveis aspectos que caracterizem a configuração dos Sistemas Estaduais de Avaliação com qualidade e gestão da educação, reafirmando a centralidade da avaliação na definição da qualidade educacional e na condução da gestão escolar.

O discurso da gestão democrática na Revista Brasileira de Política e Administração da Educação (1995-2004) de autoria de Ana Lucia Calbaiser da Silva, Jaime Farias 
e José Carlos Rothen traduz a participação da Revista Brasileira de Política e Administração da Educação (RBPAE) para as publicações na área a partir da análise dos artigos publicados no período de 1995 a 2004, contribuindo de forma significativa para a construção discursiva sobre a gestão democrática da educação brasileira.

Por fim, com o mesmo foco de análise das publicações realizadas pela Revista Brasileira de Política e Administração da Educação (RBPAE), Telma Aparecida Teles Martins Silveira e Caroline Silva Araújo, por meio do artigo Gestão democrática na Educação Infantil: uma análise da RBPAE no período de 2000 a 2012 analisa as concepções de gestão na Educação Infantil no período de $2000 \mathrm{a}$ 2012, demonstrando que a maioria dos estudos que tratam desse tema não possui a Educação Infantil como foco principal, carecendo de discussão mais profunda do que a gestão democrática representa nessa etapa da Educação Básica.

Salientamos que a Revista Brasileira de Política e Administração da Educação (RBPAE) mantém abertas chamadas para submissão de artigos, avaliados por pesquisadores de diversas subáreas que compõem o escopo deste periódico, que também poderão compor dossiês temáticos, em geral coordenados por professores pesquisadores nas áreas delineadas. A editoria agradece aos interessados e convida todos à leitura dessa edição e a novas submissões.

\section{Daniela da Costa Britto Pereira Lima}

Editora Associada

Lúcia Maria de Assis

Editora 